\author{
Marquette University \\ e-Publications@Marquette
}

School of Dentistry Faculty Research and

Publications

Dentistry, School of

$1-15-2008$

\title{
Novel Molecules for Intra-Oral Delivery of Antimicrobials to \\ Prevent and Treat Oral Infectious Diseases
}

Periathamby A. Raj

Perident Therapeutics, Inc.

Latha Rajkumar

Marquette University

Andrew R. Dentino

Marquette University, andrew.dentino@marquette.edu

Follow this and additional works at: https://epublications.marquette.edu/dentistry_fac

Part of the Dentistry Commons

\section{Recommended Citation}

Raj, Periathamby A.; Rajkumar, Latha; and Dentino, Andrew R., "Novel Molecules for Intra-Oral Delivery of Antimicrobials to Prevent and Treat Oral Infectious Diseases" (2008). School of Dentistry Faculty

Research and Publications. 266.

https://epublications.marquette.edu/dentistry_fac/266 
Marquette University

\section{e-Publications@Marquette}

\section{Dentistry Faculty Research and Publications/Department of Dentistry}

This paper is NOT THE PUBLISHED VERSION; but the author's final, peer-reviewed manuscript.

The published version may be accessed by following the link in the citation below.

Biochemical Journal, Vol. 409, No. 2 (2008): 601-609. DOI. This article is (C) Portland Press Limited and permission has been granted for this version to appear in $\underline{\mathrm{e}}-$

Publications@Marquette. Portland Press Limited does not grant permission for this article to be further copied/distributed or hosted elsewhere without the express permission from Portland Press Limited.

\section{Novel Molecules for Intra-Oral Delivery of Antimicrobials to Prevent and Treat Oral Infectious Diseases}

Periathamby Antony Raj

Perident Therapeutics, Inc., Milwaukee, WI 53219, U.S.A.

Latha Rajkumar

Division of Periodontics and Department of Surgical Sciences, School of Dentistry, Marquette University Milwaukee, WI 53233, U.S.A.

Andrew R. Dentino

Perident Therapeutics, School of Dentistry, Marquette University, Milwaukee, WI 53233, U.S.A.

Table of Contents

INTRODUCTION

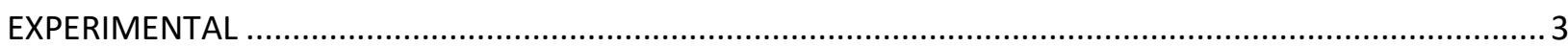

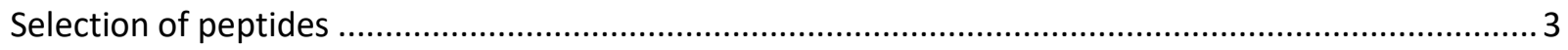




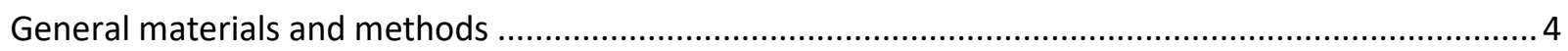

Synthesis of the bifunctional hybrid molecules (hybrid A and hybrid B)............................................ 5

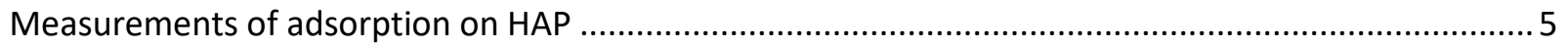

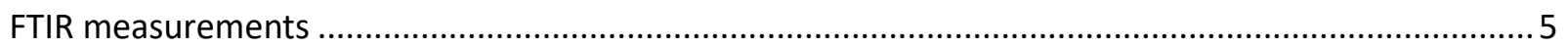

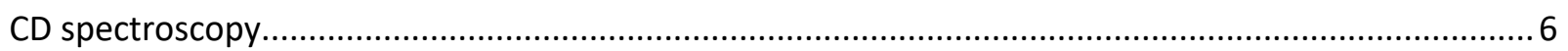

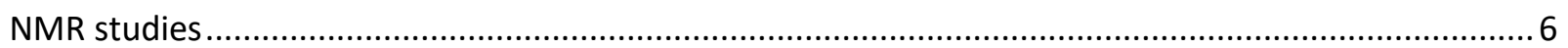

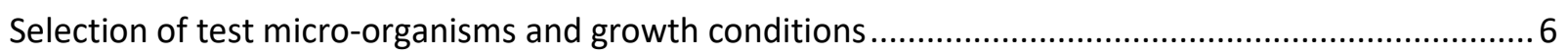

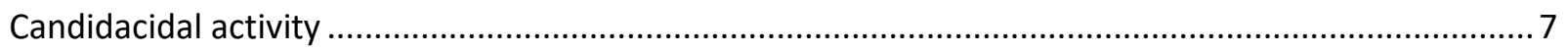

Measurement of the loss of microbial cell membrane integrity .....................................................

Measurement of the loss of $C$. albicans cell membrane integrity ..................................................... 7

Assessment of the loss of bacterial membrane integrity ................................................................. 8

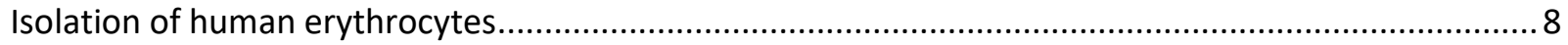

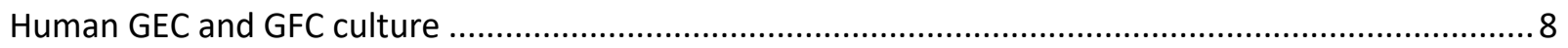

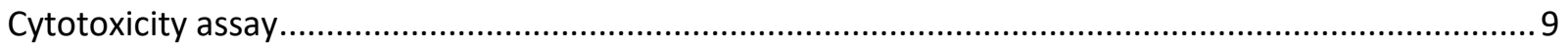

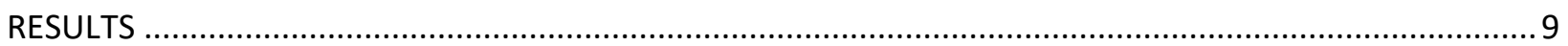

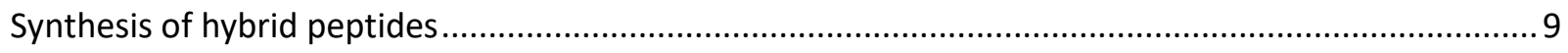

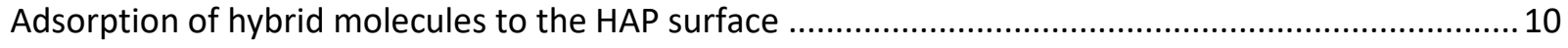

Kinetics of the antimicrobial release in human whole saliva............................................................ 11

Candidacidal activity of hybrid molecules as a function of the antimicrobial release ..........................11

Candidacidal activity of the hybrid-adsorbed HAP surface ............................................................. 12

Bactericidal activity of the hybrid-adsorbed HAP surface .............................................................. 13

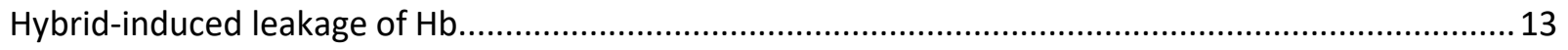

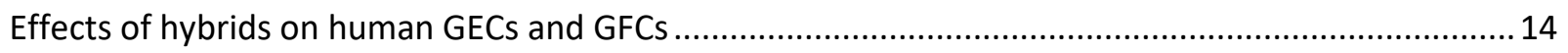

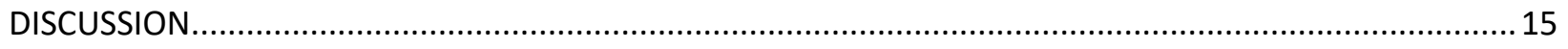

Tooth enamel-binding peptides as carriers for intra-oral delivery of therapeutics ............................15

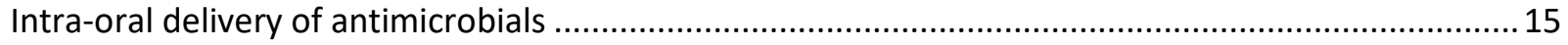

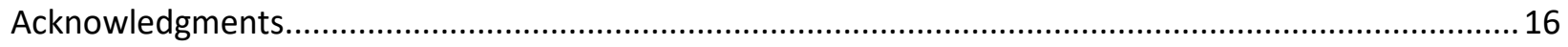

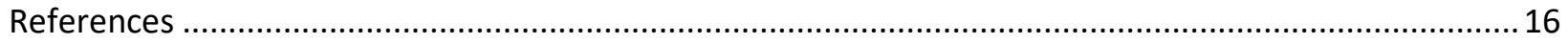

\section{INTRODUCTION}

Caries and periodontal disease remain the most common oral infectious diseases in humans, despite the use of antibiotics, fluorides and other oral health agents. Antibiotic resistance acquired by oral micro- 
organisms amplifies the need to develop innovative strategies for controlling plaque-related oral infections. ${ }^{1}$ Antimicrobial therapies for oral diseases have been in use for centuries, but have undergone rapid changes in recent years. New drug-delivery systems for common antimicrobials and novel agents to modulate the dental plaque/biofilm formation and maturation are currently emerging. ${ }^{2,3}$ Methods employed to deliver the antimicrobial agents to the site of oral infection include rinsing, irrigation, systemic administration and local application using sustained and controlled delivery devices. ${ }^{2,4}$ The efficiency of the drug-delivery system designed to target oral infections depends on its ability to deliver the drug at a bacteriostatic or bactericidal concentration and its ability to retain the medicament long enough to ensure adequate results. Since local drug delivery in the oral cavity may achieve these requirements, commercially available formulations such as minocycline microspheres, metronidazole and minocycline gels, chlorhexidine chips and doxycycline polymers are currently in use to treat periodontal disease..$^{3-5}$ In these systems, polymers encapsulating an antibiotic or antiseptic are inserted or injected into the site of infection, where they degrade and release the active agent at the site of infection. Although some of these drug-delivery devices may achieve adequate bioavailability of antimicrobials to the site of infection, there are several disadvantages and limitations with these systems, as reported previously. ${ }^{3,4}$ Therefore small molecules with high affinity for enamel and the ability to deliver antimicrobials directly to the tooth and pellicle surface would be highly desirable.

The selective adsorption of salivary proteins to the tooth surface forms the acquired enamel pellicle. These salivary molecules include mucins, $\alpha$-amylase, PRG (proline-rich glycoprotein), PRPs (proline-rich proteins), cystatins, statherin and histatins. Pellicle-forming salivary proteins have a tooth-enamelbinding domain, ${ }^{6,7}$ an antimicrobial region ${ }^{7-9}$ and a region that serves as a receptor for microbial colonization. ${ }^{10-13}$ The apatitic/tooth-surface-binding domain and an antimicrobial component could be linked by a biodegradable bond to efficiently deliver therapeutic agents intra-orally. Such a bifunctional hybrid molecule is expected to adhere to the tooth and pellicle surfaces uniformly, with a sustained release of the antimicrobial from the tooth surface inhibiting microbial colonization.

The present paper describes the synthesis of two novel intra-oral antimicrobial delivery molecules, their substantivity and the antimicrobial release kinetics in clarified human whole saliva, and their toxicity to human cells. The antimicrobial activity of the molecules adsorbed on the tooth enamel mineral [HAP (hydroxyapatite)] surface against Candida albicans and Aggregatibacter actinomycetemcomitans, previously referred to as Actinobacillus actinomycetem-comitans, is also summarized in the present paper.

\section{EXPERIMENTAL}

\section{Selection of peptides}

An analogue of the N-terminal fragment of statherin (Asp-Asp-Asp-Glu-Glu) with high affinity for the enamel surface ${ }^{6}$ has been selected as the carrier sequence. A 12-residue defensin-like peptide (Arg-LeuCys-Arg-Ile-Val-Val-Ile-Arg-Val-Cys-Arg) with a disulfide bridge between the two cysteine residues was selected as the antimicrobial, since it has been shown to possess antimicrobial activity against several oral pathogens. ${ }^{14}$ The two components were linked through the side chain of a serine/aspartic acid residue to generate two bifunctional hybrid molecules with an ester and an anhydride bond between the two components respectively (Figure 1 ). The $C^{\beta}$-carbon atoms of the serine and aspartic acid 
residues that link the carrier and the antimicrobial were ${ }^{13} \mathrm{C}$-labelled to monitor the release of the antimicrobial component from the carrier.

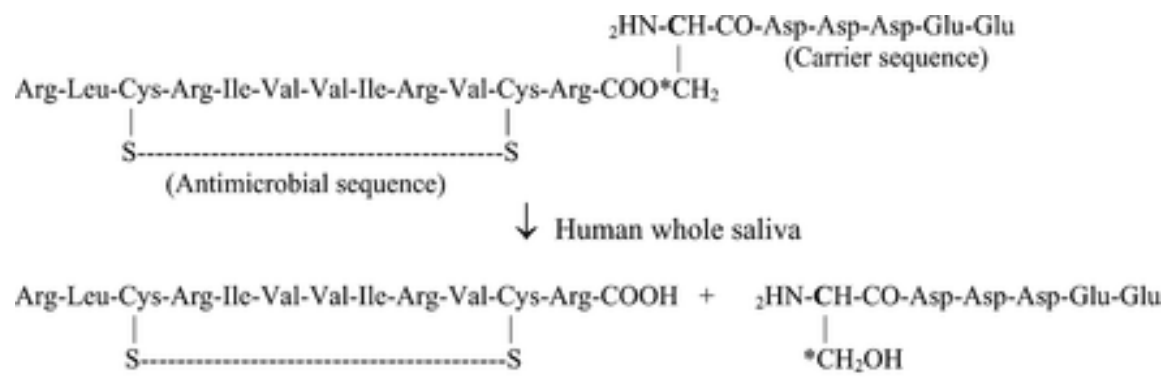

Hybrid A with an ester bond between the carrier and the antimicrobial components

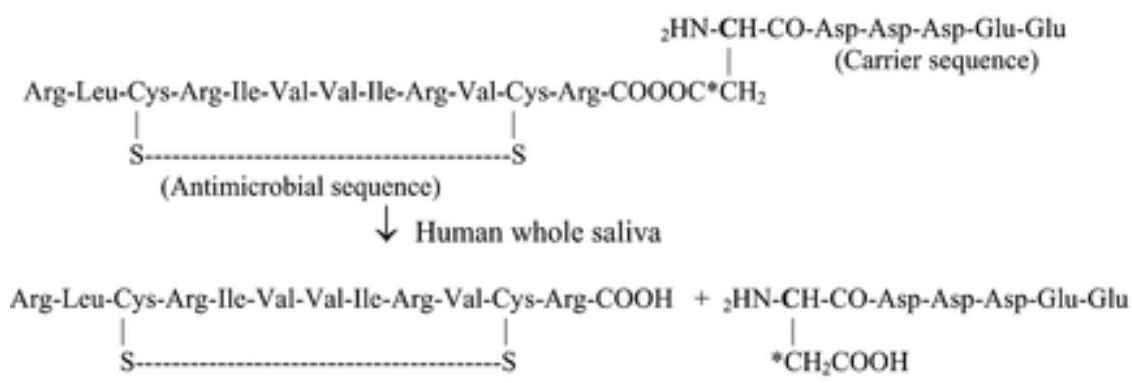

Hybrid B with an anhydride bond between the carrier and the antimicrobial components $\left[{ }^{*}\right.$ Denotes $\left.{ }^{13} \mathrm{C}\right]$

Figure 1 Sequences of hybrid $A$ and hybrid $B$

The carrier and the antimicrobial components were linked through the side chain of the ${ }^{13} \mathrm{C}$-enriched amino acid (serine residue in hybrid $\mathrm{A}$ and aspartic acid residue in hybrid $\mathrm{B}$ ) at the $\mathrm{N}$-terminus of the carrier peptide. In human saliva, the biodegradable ester and anhydride bonds dissociate, causing a sustained release of the antimicrobial component.

Among cathelicidins, defensins and histatins that are present in saliva, a defensin-derived peptide was selected. Defensins are salivary peptides as are histatins, since they are expressed and secreted by the salivary glands. ${ }^{15,16}$ Although histatins are potent antifungal peptides, they are antibacterial only at a much higher concentration than that for defensins. ${ }^{14,17,18}$ The antimicrobial peptide used in the hybrid molecule should be compatible in molecular size without hindering the enamel-binding efficacy of the carrier component. Although cathelicidin LL37 is a potent antimicrobial. ${ }^{19}$ its much larger size could mask the structure and function of the carrier molecule. Hence, a 12-residue defensin-like peptide was selected.

\section{General materials and methods}

Chemicals and solvents were of the highest purity available and used without further purification. Amino acid derivatives, Wang resin and NPN ( $N$-phenyl-1-naphthylamine) were purchased from Sigma and Bachem. The ${ }^{13} \mathrm{C}^{\beta}$-labelled serine and aspartic acid derivatives were purchased from Cambridge Isotope Laboratories. Calcein-AM (calcein-acetoxymethyl ester) and calcein were obtained from Molecular Probes. Hybrid peptides were synthesized using an Advanced Chemtech (ACT Model-90) peptide synthesizer. HPLC was carried out on a Rainin HPXL system interfaced to a Macintosh SE/30 computer, using a Rainin Dynamax $\mathrm{C}_{18}$ column $(10 \mathrm{~mm} \times 250 \mathrm{~mm}$ ) coupled with a guard column $(10 \mathrm{~mm} \times 50 \mathrm{~mm})$ 
and employing an acetonitrile/water (each containing $0.1 \%$ trifluoroacetic acid) linear gradient elution with a flow rate of $2.0 \mathrm{ml} / \mathrm{min}$. The dried peptides were hydrolysed in sealed tubes for $24 \mathrm{~h}$ at $110^{\circ} \mathrm{C}$, using $6 \mathrm{M} \mathrm{HCl}$ in the presence of $1 \%$ phenol vapour, and amino acid analysis was performed on a PerkinElmer 420A derivatizer and analyser system. The amino acid sequence of the peptide $(\sim 1 \mathrm{nmol})$ was checked by sequence analysis, using a PerkinElmer model 477A protein sequencer. FAB (fast atom bombardment) mass analysis was carried out on a VG Analytical ZAB 2-SE high-field mass spectrometer (M-Scan). A caesium ion gun was used to generate ions for the acquired spectra, which were recorded using a PDP 11-250J data system. Fluorescence studies were performed using a PerkinElmer 650-40 fluorescence spectrophotometer. The HAP crystals with a specific surface area of $29 \pm 0.3 \mathrm{~m}^{2} / \mathrm{g}$ (Brunauer-Emmett-Teller nitrogen adsorption) were prepared as described previously ${ }^{6,20}$ and characterized by X-ray powder diffraction (Nicolet/Nic diffractometer with Stoe attachment, using a position-sensitive detector in the transmission mode). The calcium to phosphate molar ratio in the HAP crystal was $1.65 \pm 0.05$.

\section{Synthesis of the bifunctional hybrid molecules (hybrid $A$ and hybrid $B$ )}

The synthesis of hybrid A and hybrid B was carried out as outlined in Supplementary Figures 1 and 2 (http://www.BiochemJ.org/bj/409/bj4090601add.htm) by using the standard Fmoc (fluoren-9ylmethoxycarbonyl) and Boc (t-butoxycarbonyl) procedures. ${ }^{14,18,21}$ The cleaved peptide containing the acetamidomethyl protecting group on the two cysteine residues was deprotected and oxidized to form the disulfide, as described previously. ${ }^{14}$ Hybrid A and hybrid B were purified and tested for homogeneity as described in the Supplementary data (http://www.BiochemJ.org/bj/409/bj4090601add.htm). The bond between the carrier and the antimicrobial components was verified by FTIR (Fourier-transform infrared) spectroscopy. The presence of a disulfide bridge was verified by CD spectroscopy.

\section{Measurements of adsorption on HAP}

Adsorption experiments were carried out as described previously. ${ }^{6,22}$ HAP beads with a specific surface area of $29.2 \pm 0.3 \mathrm{~m}^{2} / \mathrm{g}$ were used for these experiments. Known amounts of peptides were equilibrated for $4 \mathrm{~h}$ with HAP crystallites $\left(1 \times 10^{3} \mathrm{~g}\right)$ in a saturated solution $(1 \mathrm{ml})$ at $37^{\circ} \mathrm{C}$ and $\mathrm{pH} 7.4$, using an ionic strength of $0.15 \mathrm{~mol} / \mathrm{l}$. Adsorption kinetics demonstrated that equilibrium was achieved in less than $4 \mathrm{~h}$. To avoid bacterial degradation during adsorption, all peptide solutions were prepared with $0.1 \% 1,1,1$ trichloro-2-methyl-2-propanol. After adsorption, the HAP crystallites were separated from the supernatant solution by centrifugation at $250 \mathrm{~g}$ for $10 \mathrm{~min}$. The peptide-adsorbed HAP crystallites were washed with saturated solution of HAP $(2 \times 1 \mathrm{ml})$. The peptide concentration in the supernatant solutions was determined by amino acid analysis and compared with the initial concentration. Amino acid analysis indicated that adsorbed molecules on HAP were not removed during washing. A parallel experiment performed in the absence of HAP crystals showed that peptide adsorption on the reaction vessels was negligible.

\section{FTIR measurements}

ATR-FTIR (attenuated total reflectance FTIR) spectra in solution were recorded on a Bio-Rad FTS-40 spectrometer equipped with a deuterated triglycine sulfate detector and a Bio-Rad 3240-SPC computer for data acquisition and analysis. Spectra were recorded at $30^{\circ} \mathrm{C}$ by using a Micro Circle cell (SpectraTech) with a zinc selenide CIR (cylindrical internal reflectance) crystal in a stainless steel flow cell. A 1024-scan interferogram was collected at a single beam with a resolution of $2 \mathrm{~cm}^{-1}$, using a peptide concentration of $0.5 \mathrm{mM}$. The spectrometer was continuously purged with dry air to eliminate water 
vapour adsorption. Solvent and sample spectra were recorded under identical conditions, and the difference spectra were obtained, as described previously. ${ }^{9}$

\section{CD spectroscopy}

$C D$ measurements were carried out to verify the presence of the disulfide bond. An Aviv 62DS spectropolarimeter equipped with a thermostatic temperature controller and interfaced to an IBM microcomputer was used. CD spectra were recorded in a quartz cell of $0.05 \mathrm{~nm}$ path length at $30^{\circ} \mathrm{C}$, using a $1.0 \mathrm{~nm}$ bandwidth and a scanning rate of $10 \mathrm{~nm} / \mathrm{min}$ with a wavelength step of $0.2 \mathrm{~nm}$ and a time constant of $2 \mathrm{~s}$. Peptide dissolved in $10 \mathrm{mM}$ sodium phosphate buffer at pH 7.2 at a concentration of $0.1 \mathrm{mM}$ was used.

\section{NMR studies}

All $125-\mathrm{MHz}{ }^{13} \mathrm{C} 1 \mathrm{D}$ (one-dimensional)-NMR spectra were recorded on a Varian Unity Inova $500 \mathrm{MHz}$ spectrometer equipped with a SUN Sparckstation 20. A spectral width of $25157.2 \mathrm{~Hz}$, a relaxation delay of $12 \mathrm{~s}$ and an acquisition time of $1.2 \mathrm{~s}$ were used. The proton decoupler was on only during the acquisition time and off during the delay time to eliminate the influence of NOE (nuclear Overhauser effect) effects on the intensity of the ${ }^{13} \mathrm{C}$ resonances. Thus the signal intensity was dependent only on the quantity of the material for quantitative estimation. ${ }^{23,24}$ The ${ }^{13} \mathrm{C}-\mathrm{NMR}$ spectra of the hybrid molecules $(500 \mu \mathrm{M})$ in $1 \mathrm{ml}$ of clarified human whole saliva containing $5 \%{ }^{2} \mathrm{H}_{2} \mathrm{O}\left(37^{\circ} \mathrm{C}, \mathrm{pH} 7.2\right)$ at various intervals of time were recorded. Chemical shifts were referenced to tetramethylsilane $\left(\mathrm{Me}_{4} \mathrm{Si}\right)$ in a concentric capillary.

\section{Selection of test micro-organisms and growth conditions}

C. albicans is an opportunistic pathogen and is intimately associated with chronic oral infections which are increasing in the growing immunocompromised and aging populations worldwide. Moreover, in the sub-gingival flora of several adult periodontitis and AIDS patients, C. albicans has been detected. ${ }^{22,25} \mathrm{C}$. albicans also plays a significant role in DIS (denture-induced stomatitis), which is found in $20 \%$ of the aging population. ${ }^{26} \mathrm{C}$. albicans infection has been estimated to be as high as $60 \%$ among the denturewearing institutionalized subjects. ${ }^{27}$

Defensins and defensin-like antimicrobial peptide have already been reported to be active against cariogenic Lactobacillus casei, ${ }^{28}$ Streptococcus mutans and periodontopathogenic Porphyromonas gingivalis and $A$. actinomycetemcomitans. ${ }^{14}$ To demonstrate and validate the controlled and sustained antimicrobial release from the hybrid molecules and its activity, $C$. albicans and $A$.

actinomycetemcomitans were selected to represent a fungal and a bacterial organism respectively, both of which are associated with oral infectious diseases.

A clinical isolate of $C$. albicans strain from a DIS patient was used. The identity of the clinical isolate was verified by the Yeast System (Flow Laboratories). Organisms were streaked on to Sabouraud Dextrose Agar plates (Difco) and maintained at $4{ }^{\circ} \mathrm{C}$. One colony of $C$. albicans from this plate was inoculated into $10 \mathrm{ml}$ of yeast synthetic growth medium containing sucrose, salts and biotin, and incubated for $48 \mathrm{~h}$ at $25{ }^{\circ} \mathrm{C}$ in a shaker rotating at $200 \mathrm{rev}$./min to bring yeast cells into the late exponential phase of growth. The cell morphology was determined by phase-contrast microscopy and found to be uniformly blastospores. Subcultures were done every 3 days by inoculating $100 \mu \mathrm{l}$ of 3-day-old culture into $10 \mathrm{ml}$ of fresh synthetic media. 


\section{Candidacidal activity}

The candidacidal activity of the hybrid molecules was determined as a function of the release of the antimicrobial in clarified human whole saliva. The hybrid molecule was incubated with $1 \mathrm{ml}$ of saliva buffer $^{29}$ (the composition of which is shown in the Supplementary data) and $4 \mathrm{ml}$ of clarified human whole saliva such that the final hybrid concentration was $100 \mu \mathrm{M}$ kept at $\mathrm{pH}$ 7.2. The sample was divided into two and each portion was separately maintained at 37 and $-5{ }^{\circ} \mathrm{C}$, the latter to minimize the dissociation of ester/anhydride bond of the hybrid. Over time, aliquots of both samples ( $25 \mu \mathrm{l})$ were examined for candidacidal activity, as described previously. ${ }^{8,30}$ The assays were performed on stationary C. albicans cells in the presence or absence of the hybrid $(25 \mu \mathrm{l})$, as described previously. ${ }^{30}$ Briefly, $C$. albicans cells were washed with $10 \mathrm{mM}$ sodium phosphate buffer $(\mathrm{pH} 7.4)$ and resuspended at $1.8 \times 10^{5}$ cells/ml. A cell suspension of $25 \mu \mathrm{l}$ was mixed with $25 \mu \mathrm{l}$ of hybrid in saliva and then incubated with shaking at $37^{\circ} \mathrm{C}$ for $1.5 \mathrm{~h}$. Control cultures were incubated with $25 \mu \mathrm{l}$ of saliva and saliva buffer without the hybrid peptide. The reaction was stopped by the addition of $360 \mu \mathrm{l}$ of yeast nitrogen base, and $40 \mu \mathrm{l}$ of the suspension was spread on to Sabouraud dextrose agar plates and incubated for $48 \mathrm{~h}$ at $37^{\circ} \mathrm{C}$. Candidacidal assays were performed in duplicate or triplicate. Loss of viability was calculated as $\{1-$ [(number of colonies from suspensions with hybrid)/(number of colonies from suspension with no hybrid)]\} $\times 100$.

\section{Measurement of the loss of microbial cell membrane integrity}

A. actinomycetemcomitans strain $\mathrm{Y} 4$ was maintained on tryptic soy agar plates containing yeast extract $(0.5 \%)$. For liquid culture, cells were grown in the respective broths. All experiments were carried out in an anaerobic chamber $\left(85 \% \mathrm{~N}_{2}, 10 \% \mathrm{H}_{2}\right.$ and $5 \% \mathrm{CO}_{2}$; Coy Laboratory Products) and the purity of the bacterial strain was confirmed routinely as described previously. ${ }^{7,14}$

The efficacy of peptides to induce loss of cell membrane integrity has been well correlated with their microbicidal activity. $22,30,31$ Hence, the efficacy of the hybrid-bound HAP surface in inducing disruption of cell membrane permeability was determined as a measure of microbicidal activity. Calcein-AM and NPN were used as fluorescent probes to examine $C$. albicans and A. actinomycetemcomitans membrane permeability respectively. The peptide-induced leakage of a fluorescent probe (calcein-AM) incorporated within C. albicans membranes, and the peptide-induced incorporation of the membraneexcluded probe (NPN) into bacterial membranes, were monitored.

\section{Measurement of the loss of $C$. albicans cell membrane integrity}

C. albicans cells were loaded with the fluorescent probe calcein-AM. The calcein-AM is non-fluorescent within the cell. The cellular esterases convert the ester into an acid, the fluorescence of which was quenched within the cell membrane. The fluorescence was de-quenched when calcein leaks into the extracellular environment. Peptide-induced leakage of calcein was monitored by measuring the dequenching of fluorescence at $520 \mathrm{~nm}$ by exciting the system at $495 \mathrm{~nm}$. The assay was performed as we described previously. ${ }^{22,30} \mathrm{C}$. albicans cells ( 3 days old) were washed twice with $20 \mathrm{ml}$ of PBS and the concentration was adjusted to $10^{7}$ cells/ml. Calcein-AM ( $5 \mu \mathrm{l}$ of $1 \mathrm{mM}$ ) was added to $1 \mathrm{ml}$ of cells. The cells were incubated for $4 \mathrm{~h}$ at room temperature $\left(25^{\circ} \mathrm{C}\right)$ and then washed extensively with $10 \mathrm{mM}$ PBS to remove unincorporated calcein-AM. For the assay, $100 \mu \mathrm{l}$ of the calcein-AM-loaded cells (105 cells $/ \mathrm{ml}$ ) were mixed with $50 \mathrm{mg}$ of hybrid-adsorbed HAP beads. The final volume in the cuvette was $1 \mathrm{ml}$. The fluorescence intensity $\left(F_{a}\right)$ was measured at $520 \mathrm{~nm}$ using a $\lambda_{\text {ex }}$ of $495 \mathrm{~nm}$ at regular intervals of time for $10 \mathrm{~h}$. The cell suspension was stirred gently for $10 \mathrm{~s}$ after each measurement and at regular 
intervals to ensure cell-bead contact. The fluorescence intensity at $520 \mathrm{~nm}$ of cells and clean untreated HAP beads after 15 min was taken as the background fluorescence $\left(F^{b}\right)$. The total fluorescent content of the cell was determined by incubating the cells at $100{ }^{\circ} \mathrm{C}$ for $5 \mathrm{~min}\left(\mathrm{~F}_{\mathrm{t}}\right)$. The minimal non-specific leakage of fluorescence from cells alone was determined after $6 \mathrm{~h}$ and subtracted from that obtained from cells and hybrid-bound HAP. The percentage release of calcein $=\left[\left(F_{a}-F_{b}\right) / F_{t}\right] \times 100$. The fluorescence intensity measurement of cells and free HAP beads was used as the control.

\section{Assessment of the loss of bacterial membrane integrity}

The membrane permeability induced by the released antimicrobial from the hybrid-adsorbed HAP was assessed by the extent the antimicrobial permeabilized the outer bacterial membrane. This was determined by using the neutral hydrophobic probe NPN. Antimicrobial peptides bind to lipopolysaccharide, displacing the native bivalent cations and disrupting the outer membrane permeability. NPN is excluded from an intact outer membrane. ${ }^{32,33}$ However, when the permeability of the bacterial outer membrane is disrupted, NPN enters the membrane, resulting in fluorescence. Briefly, $1 \mathrm{ml}$ of mid-exponential-phase $A$. actinomycetemcomitans strain $Y 4$ cell suspension was incubated with $5 \mu \mathrm{l}$ of $1 \mathrm{mM}$ NPN and then treated with $50 \mathrm{mg}$ of hybrid-bound HAP. Fluorescence intensity was measured at $420 \mathrm{~nm}$ using a $\lambda_{\text {ex }}$ of $340 \mathrm{~nm}$ at regular intervals of time for $10 \mathrm{~h}$. The cell suspension was stirred gently for $10 \mathrm{~s}$ after each measurement and at regular intervals to ensure cell-bead contact. The percentage intake of NPN was calculated, as described in the previous section, from the formula: percentage intake of $N P N=\left[\left(F_{a}-F_{b}\right) / F_{t}\right] \times 100$. The fluorescence intensity measurement of cells and free HAP beads was used as the control.

\section{Isolation of human erythrocytes}

The leakage of $\mathrm{Hb}$ from human erythrocytes was monitored by using standard procedures. ${ }^{34}$ Briefly, blood obtained by venipuncture from normal healthy volunteers with informed consent was collected in lithium-heparinized tubes, centrifuged at $450 \mathrm{~g}$ at $4{ }^{\circ} \mathrm{C}$ for short times ( $5 \mathrm{~min}$ ), and the plasma and buffy coat were removed. Erythrocytes were then washed three times with PBS at $4{ }^{\circ} \mathrm{C}$ before being dispersed in PBS, counted in a haemocytometer and used on the day of harvesting. After washing, cells were resuspended in PBS and adjusted to give a final concentration of $1 \times 10^{8}$ cells $/ \mathrm{ml}$. Ouabain $\left(10^{-6} \mathrm{M}\right)$ was added to the final cell suspension to inhibit the membrane-bound $\mathrm{Na}^{+} / \mathrm{K}^{+}$ATPase pump. For the determination of leakage of $\mathrm{Hb}, 2 \mathrm{ml}$ of cell suspension $\left(5 \times 10^{7}\right.$ cells $\left./ \mathrm{ml}\right)$ in PBS was incubated for $1 \mathrm{~h}$ at $37^{\circ} \mathrm{C}$ with the test material. After the incubation, the cells were centrifuged at $1500 \mathrm{~g}$ for $5 \mathrm{~min}$ and washed three times with PBS for $10 \mathrm{~s}$. The supernatant was collected and the degree of haemolysis was determined by comparing the $\mathrm{Hb}$ concentration in the supernatant with that in the original cell suspension by measuring the absorbance (A) at $540 \mathrm{~nm} ; 0 \%$ haemolysis and $100 \%$ haemolysis were determined by suspending cells in PBS and 1\% Triton X-100 respectively. Salivary histatin 5 and melittin were used as negative and positive controls respectively.

\section{Human GEC and GFC culture}

Human GECs (gingival epithelial cells) and GFCs (gingival fibroblast cells) were cultured using an explant technique according to previously described procedures with slight modifications. ${ }^{35,36}$ Tissue specimens were derived from histologically normal areas of gingiva collected during elective periodontal/oral surgical procedures with the consent of otherwise-healthy patients. The GECs were isolated by using standard procedures. ${ }^{35,37}$ After collection, gingival tissue specimens were placed in sterile PBS supplemented with penicillin, streptomycin and amphotericin B. The tissues were then incubated with 
0.4\% dispase (BM Biochemicals) overnight at room temperature. The surface epithelium was separated, minced and placed in sterile PBS containing trypsin $(0.55 \%)$ and EDTA $(0.53 \mathrm{mM})$ to dissociate the intact epithelium into single cell suspensions. Cells were collected by centrifugation and cultured in serumfree, sterile keratinocyte basal medium supplemented with epidermal growth factor $(0.1 \mathrm{ng} / \mathrm{ml})$, insulin $(5 \mu \mathrm{g} / \mathrm{ml})$, cortisol $(0.5 \mu \mathrm{g} / \mathrm{ml}), \mathrm{CaCl}_{2}(0.15 \mathrm{mM})$, bovine pituitary extract $(20 \mu \mathrm{l} / \mathrm{ml})$, gentamicin $(50 \mu \mathrm{g} / \mathrm{ml})$ and amphotericin B (50 ng/ml) (KGM; Clonetics Corp.). Tissue culture dishes (100 mm) precoated with murine collagen type IV $(5 \mathrm{mg} / \mathrm{ml})$ were seeded with stock cultures of cells which had been stored in liquid nitrogen, and incubated at $37^{\circ} \mathrm{C}$ in an air $/ 5 \% \mathrm{CO}_{2}$ atmosphere until confluent growth was attained. Cells were removed from the dishes by trypsin treatment (1xtrypsin-EDTA; Fisher Scientific) for $5 \mathrm{~min}$ at room temperature. The cells were harvested by centrifugation at $800 \mathrm{~g}$ for $5 \mathrm{~min}$ and resuspended in KGM medium. Cell cultures from the second and third passages were used for testing. After separating the epithelium, GFCs were cultured by the procedure reported previously. ${ }^{36}$ Tissues were minced using sterile techniques and washed twice with PBS supplemented with antibiotics (100 units/ml penicillin, $100 \mathrm{mg}$ of streptomycin and $0.25 \mu \mathrm{g} / \mathrm{ml}$ fungizone). Explants were placed in 60$\mathrm{mm}$ Petri dishes and maintained in Dulbecco's modified Eagle's medium supplemented with $10 \%(\mathrm{v} / \mathrm{v}$ ) FBS (fetal bovine serum) and antibiotics, as described above. Cultures were maintained at $37{ }^{\circ} \mathrm{C}$ in a humidified atmosphere of $5 \% \mathrm{CO}_{2}$ and $95 \%$ air. Confluent cells were detached by treatment with $0.25 \%$ trypsin and $0.05 \%$ EDTA for 5 min, and aliquots of cells were subcultured with the same medium. Cell cultures from the third to eighth passages were used for investigation.

\section{Cytotoxicity assay}

The effect of hybrid molecules on human cells was determined by the colorimetric assay, which is based on the ability of live but not dead cells to reduce the MTT [3-(4,5-dimethylthiazol-2-yl)-2,5-diphenyl-2Htetrazolium bromide] to a blue formazan product. ${ }^{38,39}$ The MTT assay in a 96 -well plate was performed to monitor cell survival and proliferation. MTT assay was carried out by measuring dehydrogenase activity as described previously, ${ }^{40,41}$ with minor modifications. Briefly, $1 \times 10^{4}$ cells per well were seeded on to a 96-well plate and left overnight. Serial dilution of various extracts $(6.25,12.5,25,50$ and $75 \mu l$, prepared in the same solvent) in $100 \mu \mathrm{l}$ volume was added, and cells were treated for $24 \mathrm{~h}$. After treatment, $50 \mu \mathrm{l}$ of MTT solution (1 mg/ml in PBS) was added to each well and incubated for another $4 \mathrm{~h}$ at $37^{\circ} \mathrm{C}$. DMSO $(150 \mu \mathrm{l})$ was added to each well and the plates were shaken to ensure the dissolution of crystals. Culture viability was determined by measuring, spectrophotometrically, the reduced MTT in a dual-beam microtitre plate reader (Molecular Devices tunable microplate reader) at $590 \mathrm{~nm}$ with a $630 \mathrm{~nm}$ reference. Four wells were used for each experimental group.

\section{RESULTS}

\section{Synthesis of hybrid peptides}

The synthetic scheme and the purification procedure yielded hybrid $A$ and hybrid $B$ in the pure state (100\%). The percentage yield was $96 \%$ with the acetamidomethyl protecting group on the two cysteine residues. The formation of intra-molecular disulfide between the two cysteine residues was accomplished in a very dilute solution. After evaporation and purification, the percentage yield of the final product was $65 \%$.

Analytical HPLC analysis verified the purity of the hybrid peptides. Amino acid analyses were consistent with the amino acid composition of the respective hybrid molecules. Amino acid sequence analyses 
verified the presence of amino acid residues corresponding to the carrier and antimicrobial sequences. The FAB mass spectra showed intense molecular ion clusters centred at $m / z 2275$ and 2303 that are consistent with the molecular masses of hybrid $A$ and hybrid $B$ respectively. The molecular ions are also consistent with the presence of the disulfide bridge and the ${ }^{13} \mathrm{C}^{\beta}$-enriched amino acid residue that connects the antimicrobial and the carrier components. ${ }^{42,43}$ The $\mathrm{CO}$ stretching band in the FTIR spectra that occurred between 1725 and $1740 \mathrm{~cm}^{-1}$ verified the presence of an ester bond in hybrid $\mathrm{A}$, whereas the two bands between 1800 and $1900 \mathrm{~cm}^{-1}$ separated by approx. $65 \mathrm{~cm}^{-1}$ showed the carbonyl stretch corresponding to the anhydride linkage in hybrid B. ${ }^{44} \mathrm{Hybrid} \mathrm{A}$ and hybrid $\mathrm{B}$ exhibited a weak negative $n-\sigma^{*}$ CD band (Supplementary Figure 3 at http://www.BiochemJ.org/bj/409/bj4090601add.htm) at approx. $265-270 \mathrm{~nm}$ (molar ellipticity $\cong-5000-6000 \mathrm{deg} \cdot \mathrm{cm}^{2} \cdot \mathrm{dmol}-{ }^{1}$ ), characteristic of the disulfide bond that is normally observed between 240 and $300 \mathrm{~nm} .{ }^{45}$ Similar CD bands have been observed and reported for oligopeptides containing a disulfide bridge. . $^{8,14,18}$

\section{Adsorption of hybrid molecules to the HAP surface}

The adsorption, $Q\left(\mathrm{~mol} / \mathrm{m}^{2}\right)$, of hybrids on the HAP surface measured at various equilibrium concentrations, $C$ (molar), was determined and compared with that of salivary statherin, as described previously. ${ }^{46}$ The affinity coefficient, $K$ (litre/mol), and the maximum number of adsorption sites, $\mathrm{N}$ $\left(\mathrm{mol} / \mathrm{m}^{2}\right)$, calculated by using the Langmuir equation, ${ }^{46} \mathrm{C} / \mathrm{Q} 1=K N+\mathrm{C} / \mathrm{N}$, are provided in Table 1 . Hybrid $\mathrm{A}$ and hybrid B exhibited high relative affinity for HAP with the $K$ values of $9.0 \pm 1.8$ and $9.2 \pm 1.7$ litres $/ \mathrm{mol}$ respectively (Table 1 ). The extent of adsorption on HAP and the affinity coefficients were quite comparable with those of salivary statherin (Table 1), which has been reported to have the highest affinity for the HAP surface. ${ }^{6}$ The affinity coefficient $K$ (litre/mol), and the maximum number of adsorption sites, $N\left(\mathrm{~mol} / \mathrm{m}^{2}\right)$, observed for salivary statherin (Table 1 ) were consistent with those reported previously. ${ }^{6,20}$ Affinity coefficient values observed for hybrid $A$ and hybrid $B$ suggested that both the molecules could efficiently bind to the tooth enamel mineral surface. Even though salivary statherin and the hybrid molecules have comparable affinity coefficients, hybrid A and hybrid B showed a higher maximum adsorption, suggesting that a greater number of smaller molecules were able to interact per unit surface area of HAP than the longer parent molecule. The antimicrobial at the Nterminus of the carrier did not seem to alter the affinity for HAP surface.

Table 1 Langmuir parameters for salivary statherin and hybrid molecules $K$ and $N$ values observed for salivary statherin are consistent with those reported previously. ${ }^{6,20}$

\begin{tabular}{|l|l|l|}
\hline Peptide & $K \times 10^{-6}($ litre $/ \mathrm{mol})$ & $\mathrm{N} \times 10^{6}\left(\mathrm{~mol} / \mathrm{m}^{2}\right)$ \\
\hline Statherin & $11.2 \pm 1.1$ & $0.44 \pm 0.1$ \\
\hline Hybrid A & $9.0 \pm 1.8$ & $1.9 \pm 0.1$ \\
\hline Hybrid B & $9.2 \pm 1.7$ & $2.0 \pm 0.2$ \\
\hline
\end{tabular}

The adsorption of salivary statherin and its fragments on HAP mineral is a real equilibrium system as reported previously. ${ }^{6,20}$ As mentioned in the Experimental section, previous adsorption experiments showed that equilibrium was achieved in less than 4 h. ${ }^{6,20}$ The susceptibility of the ester and anhydride linkages in hybrid $A$ and hybrid $B$ respectively could influence the equilibrium. However, ${ }^{13} \mathrm{C}-\mathrm{NMR}$ data reported in the present paper suggested that the dissociation of the hybrid was slow and expected to be minimal within $4 \mathrm{~h}$. Hence, the affinity constant values determined were well within the error limits. 


\section{Kinetics of the antimicrobial release in human whole saliva}

The $C^{\beta}$-carbon atoms of the serine and aspartic acid residues that connected the carrier and the antimicrobial in hybrid $A$ and hybrid $B$ respectively were enriched with ${ }^{13} \mathrm{C}$ to monitor the release of the antimicrobial by ${ }^{13} \mathrm{C}$-NMR spectroscopy. Since the natural abundance of ${ }^{13} \mathrm{C}$ is only $1.1 \%$, the resonance intensities of all other carbons merged with the noise levels except the ${ }^{13} \mathrm{C}^{\beta}$-carbons of the ${ }^{13} \mathrm{C}$-enriched serine and aspartic acid residues. The integrated intensity of the ${ }^{13} \mathrm{C}^{\beta}$ resonances was monitored to determine the extent of release of the antimicrobial in saliva. Quantitative estimation of molecules based on the integrated intensity of ${ }^{13} \mathrm{C}$ resonance has been well documented ${ }^{23,24}$ The ${ }^{13} \mathrm{C}$-NMR spectra of hybrid $A$ and hybrid $B$ (each $500 \mu \mathrm{M}$ ) in clarified human whole saliva recorded at $37^{\circ} \mathrm{C}$ and $\mathrm{pH} 7.2$ at various intervals of time are provided in the Supplementary data. As described in the Supplementary data, the integrated intensity of $\mathrm{C}^{\beta} \mathrm{H}_{2} \mathrm{OH}$ and $\mathrm{C}^{\beta} \mathrm{H}_{2} \mathrm{COOH}$ over time was used to determine the kinetics of release of the antimicrobial from hybrid $A$ and hybrid $B$ respectively (see Supplementary Figure 4 at http://www.BiochemJ.org/bj/409/bj4090601add.htm). As described in Figure 2(A), the increase in the integrated intensity of $\mathrm{C}^{\beta} \mathrm{H}_{2} \mathrm{OH}$ plotted over time suggested that $50 \%$ of hybrid $\mathrm{A}$ dissociated in clarified human whole saliva over a period of $32 \mathrm{~h}$, indicating that a sustained release of the antimicrobial could be achieved over a period of more than $60 \mathrm{~h}$. The increase in the integrated intensity of $\mathrm{C}^{\beta} \mathrm{H}_{2} \mathrm{COOH}$ over time suggested that $50 \%$ of hybrid $\mathrm{B}$ dissociated over a period of $20 \mathrm{~h}$ (Figure $2 \mathrm{~A}$ ), indicating that the antimicrobial could be released in saliva over a period of $40 \mathrm{~h}$. The results suggested that in clarified human whole saliva, hybrid $A$ and hybrid $B$ could substantially release the antimicrobial over a period of 60 and $40 \mathrm{~h}$ respectively. Under similar conditions, the anhydride linkage between the carrier and the antimicrobial released the antimicrobial faster than the ester bond in hybrid $A$ (Figure 2A).
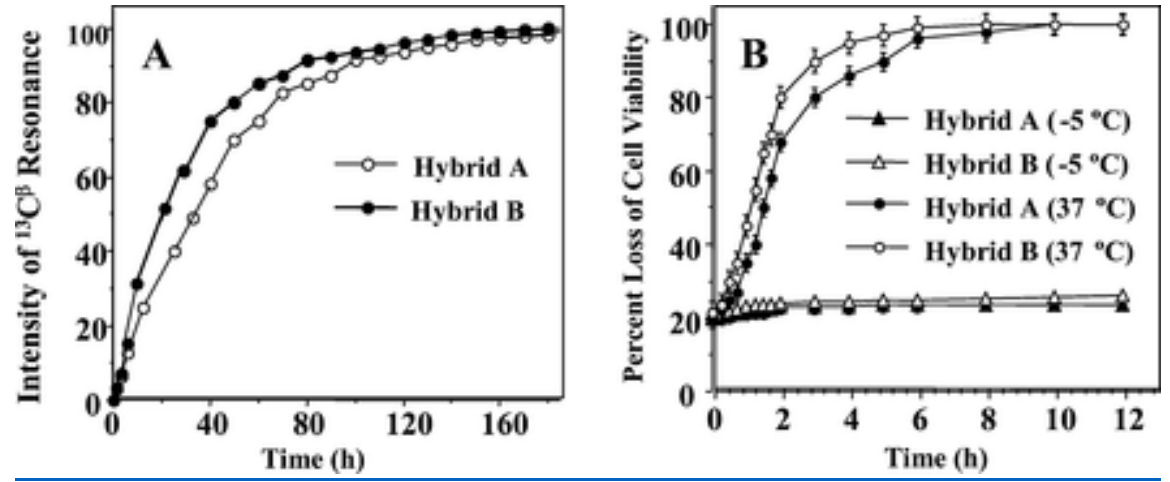

Figure 2 Kinetics of the release of the antimicrobial from the carrier

(A) The dissociation of the ester and anhydride bonds in hybrid $A$ and hybrid $B$ respectively as determined by the increase in the integrated intensity of the ${ }^{13} \mathrm{C}$ resonances of $\mathrm{C}^{\beta} \mathrm{H}_{2} \mathrm{OH}$ and $\mathrm{C}^{\beta} \mathrm{H}_{2} \mathrm{COOH}$ in hybrid $A$ and hybrid $B$ respectively over time. Peptides $(500 \mu \mathrm{M})$ were dissolved in $1 \mathrm{ml}$ of human clarified whole saliva containing $5 \%$ ${ }^{2} \mathrm{H}_{2} \mathrm{O}$ at $37^{\circ} \mathrm{C}$ and $\mathrm{pH}$ 7.2. (B) Percentage loss of viability of C. albicans (DIS) induced by hybrid A and hybrid B in clarified human whole saliva maintained at $-5^{\circ} \mathrm{C}$ and at $37^{\circ} \mathrm{C}$ over time. Hybrid molecules were dissolved in $1 \mathrm{ml}$ of saliva buffer and $3 \mathrm{ml}$ of clarified human whole saliva (at pH 7.2 and a peptide concentration of $100 \mu \mathrm{M}$ ). Samples were maintained separately at 37 and $-5{ }^{\circ}$ C. Aliquots were examined for candidacidal activity over time as described in the Experimental section. Results are means \pm S.D. for duplicate determinations from three different experiments.

\section{Candidacidal activity of hybrid molecules as a function of the antimicrobial release} The candidacidal activity of hybrid $A$ and hybrid $B$ in clarified human whole saliva $(100 \mu \mathrm{M})$ maintained at $37^{\circ} \mathrm{C}$ and $-5^{\circ} \mathrm{C}$ is provided in Figure $2(\mathrm{~B})$. The loss of cell viability of the hybrid molecules maintained 
at $37^{\circ} \mathrm{C}$ was found to be approx. $20 \%$ at the initial time (Figure 2B). This might be due to the intact hybrid molecule. The increase in the candidacidal activity was not significant for up to nearly $1 \mathrm{~h}$. After this period, the percentage loss of viable cells increased over time, and $90 \%$ killing was achieved within $5 \mathrm{~h}$ for hybrid $\mathrm{A}$ (Figure $2 \mathrm{~B}$ ) and $3 \mathrm{~h}$ for hybrid B. However, for samples maintained at $-5^{\circ} \mathrm{C}$, the percentage loss of viable cells did not increase with time, suggesting that the dissociation of the hybrid molecules was minimal at low temperature and reflected the activity of the intact molecule, since the dissociation of the ester and anhydride bonds was expected to be minimal at this temperature. The results suggested that hybrid $A$ and hybrid $B$ released the antimicrobial over time in human saliva at $37^{\circ} \mathrm{C}$ and enhanced the candidacidal activity (Figure $2 \mathrm{~B}$ ). The increase in the candidacidal activity over time was consistent with the ${ }^{13} \mathrm{C}-\mathrm{NMR}$ data and the kinetics of the release of the antimicrobial from the hybrid molecules (Figure $2 \mathrm{~A}$ ).

\section{Candidacidal activity of the hybrid-adsorbed HAP surface}

Hybrid-adsorbed HAP beads obtained by equilibration with the hybrid concentration $\left(4.0 \times 10^{-5} \mathrm{~mol} / \mathrm{l}\right)$ were used to determine the candidacidal activity of peptides in a bound state on the mineral surface. Incubation of calcein-AM-loaded C. albicans with the hybrid-adsorbed HAP beads caused a steady increase in fluorescence intensity over time measured at $520 \mathrm{~nm}$, when excited at $490 \mathrm{~nm}$. The increase in fluorescence intensity was measured and the percentage release of the fluorescent probe from the $C$. albicans membrane over time is shown in Figure 3(A). The increase in fluorescence intensity was not significant for $0.5 \mathrm{~h}$. After this time, a steady significant enhancement in fluorescence intensity was observed for hybrid A- and hybrid B-adsorbed HAP surfaces, as compared with that of the free HAP beads (Figure $3 \mathrm{~A}$ ). The result suggested the leakage of the fluorescent probe calcein-AM from $C$. albicans membrane, as a consequence of the increased membrane permeability and the damage caused by the antimicrobial component of the hybrid molecules. Collectively, the results suggested that the antimicrobial component of the hybrid was released over time from the HAP surface disrupting the $C$. albicans membrane.
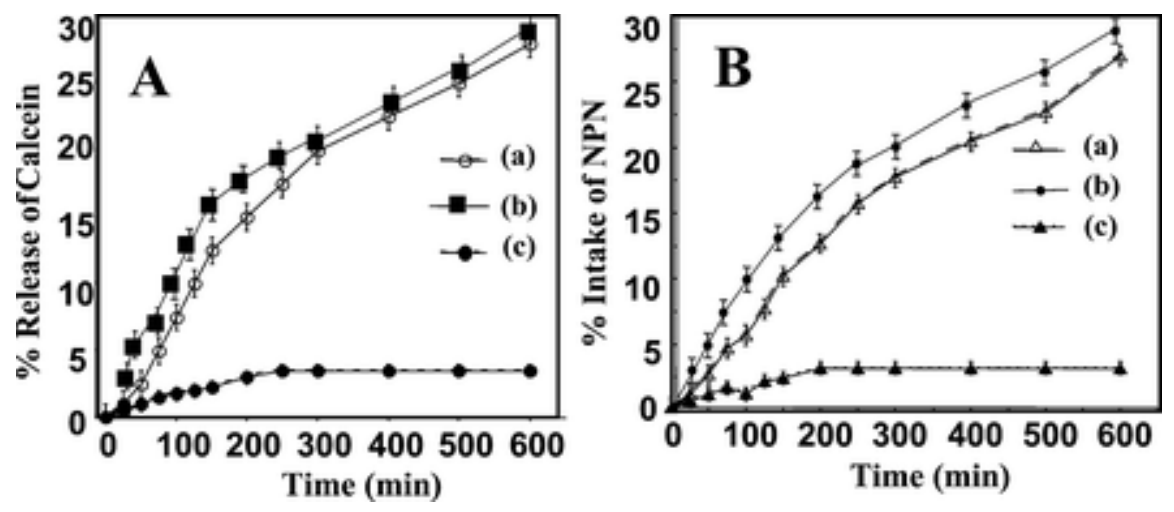

Figure 3 Candidacidal activity of hybrid-molecule-adsorbed HAP surface

(A) Candidacidal activity as determined by the percentage release of calcein from $C$. albicans membrane. Calcein release induced by the antimicrobial released from (a) hybrid A-adsorbed HAP surface, (b) hybrid B-adsorbed HAP surface and (c) control HAP surface. (B) Bactericidal activity of hybrid-molecule-adsorbed HAP surfaces as determined from the percentage intake of NPN into A. actinomycetemcomitans cell membrane. The percentage intake of NPN induced by the antimicrobial released from (a) hybrid A-adsorbed HAP surface, (b) hybrid Badsorbed HAP surface and (c) control HAP surfaces. Experiments were carried out at $37^{\circ} \mathrm{C}$ and pH 7.2. Results are means \pm S.D. for duplicate determinations from three different experiments. 


\section{Bactericidal activity of the hybrid-adsorbed HAP surface}

Hybrid-adsorbed HAP beads were also used to determine the bactericidal activity against $A$.

actinomycetemcomitans. The efficacy of the antimicrobial component of the hybrid to permeabilize the bacterial membrane was determined by using the fluorescent probe NPN. Incubation of $A$.

actinomycetemcomitans cells with the hybrid-adsorbed HAP resulted in an increased fluorescence over

time. The increase in fluorescence intensity was found to be slow for the initial $0.5 \mathrm{~h}$. After this period, a steady increase in fluorescence was observed over time for HAP surfaces coated with hybrid $A$ and hybrid $B$. The percentage intake of NPN into the bacterial membrane calculated from the fluorescence intensity over time is shown in Figure 3(B). As compared with the control HAP, which has no hybrid on its surface, hybrid A- and hybrid B-adsorbed HAP surfaces showed a significant increase in the percentage intake of NPN (Figure 3B). The result suggested the incorporation of NPN into the bacterial membrane due to increased membrane permeability caused by the antimicrobial component released from the respective HAP surface. Collectively, the results suggested that the antimicrobial component of the hybrid was released over time from the HAP surface causing the A. actinomycetemcomitans cell membrane to permeabilize (Figure 3B).

\section{Hybrid-induced leakage of $\mathrm{Hb}$}

The percentage release of $\mathrm{Hb}$ as a function of molar concentration of peptides is described in Figure 4. Hybrid A and hybrid B exhibited minimal haemolysis over the concentration range of $0-250 \mu \mathrm{M}$, suggesting that these molecules did not permeabilize human erythrocytes, although they exhibited marked influence on microbial cell membranes. Melittin is known to permeabilize human erythrocytes and it exhibited a significant increase in percentage haemolysis (Figure 4). Salivary histatin 5, which is expected to be non-toxic, appeared to exhibit some haemolytic activity at a high concentration. However, the hybrid molecules did not affect human erythrocyte membrane up to a concentration of $250 \mu \mathrm{M}$. 


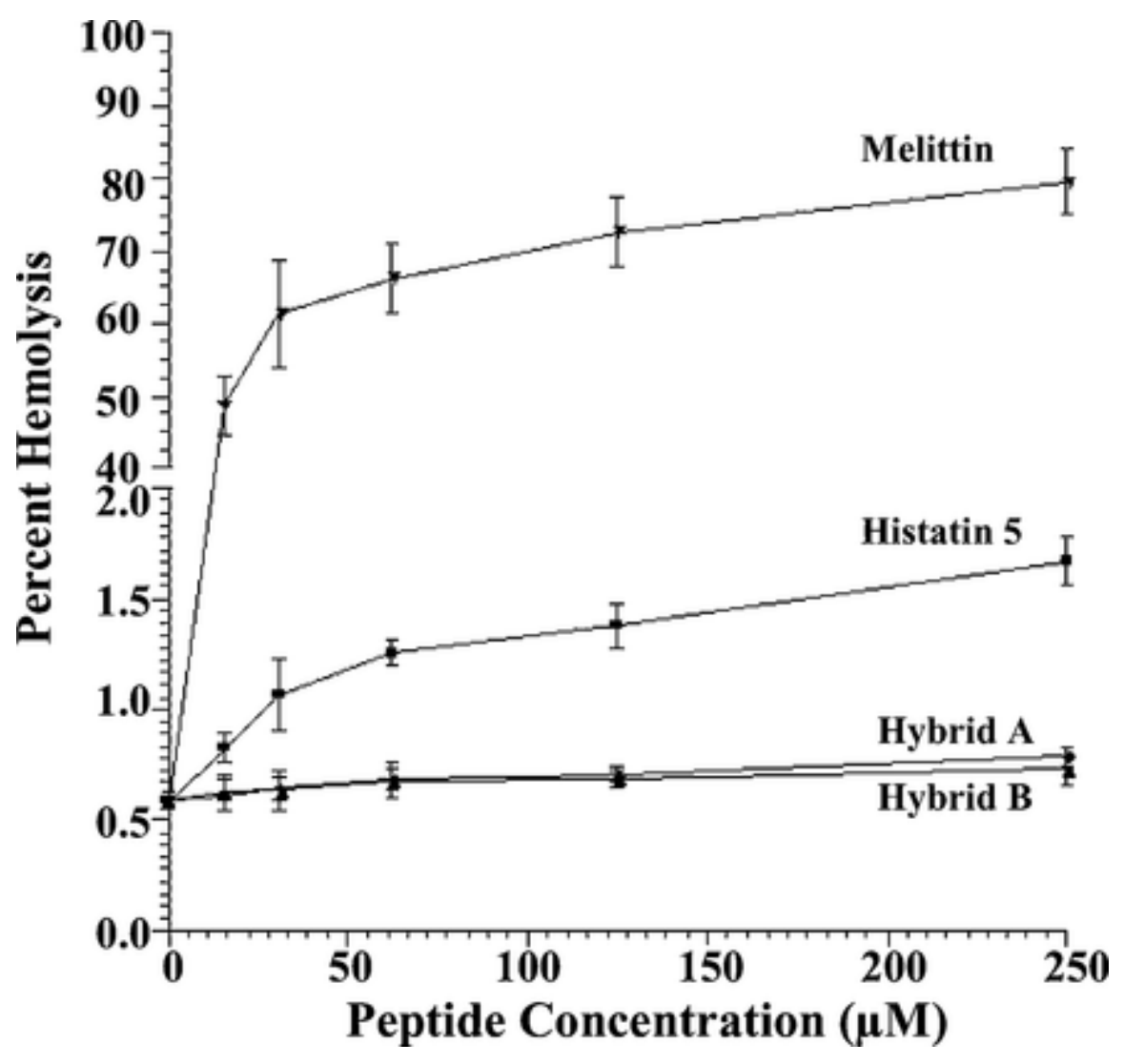

Figure 4 Effect of hybrid molecules on human erythrocytes

The leakage of $\mathrm{Hb}$ was determined by measuring the absorbance at $540 \mathrm{~nm}$. The percentage haemolysis was determined at $37^{\circ} \mathrm{C}$ for various peptide concentrations; $0 \%$ haemolysis and $100 \%$ haemolysis were determined by suspending the cells in PBS and 1\% Triton X-100 respectively. Salivary histatin 5 and melittin were used as the negative and positive controls respectively. Results are means \pm S.D. for duplicate determinations from three different experiments.

\section{Effects of hybrids on human GECs and GFCs}

The MTT assay was used to determine the viability and proliferation of human GECs and GFCs. When these cells were exposed to hybrid A or hybrid B (at 62.5 and $250 \mu \mathrm{M}$ ), the effects on cell viability and proliferation over time are described in Figure 5. Chlorhexidine, which is currently used as the gold standard for oral antiseptics, was examined as the positive control. Even at the concentration of $250 \mu \mathrm{M}$, neither of the hybrid molecules affected cell viability over a period of more than $72 \mathrm{~h}$. In addition, cell proliferation was not affected by the presence of the hybrid molecules (Figure 5). On the other hand, even at a much lower concentration $(125 \mu \mathrm{M})$, cell viability and growth were significantly affected, when human GECs and GFCs were exposed to chlorhexidine which was consistent with previous reports. ${ }^{47,48}$ The results suggested that hybrid $A$ and hybrid $B$ are not toxic to human GECs and GFCs. 

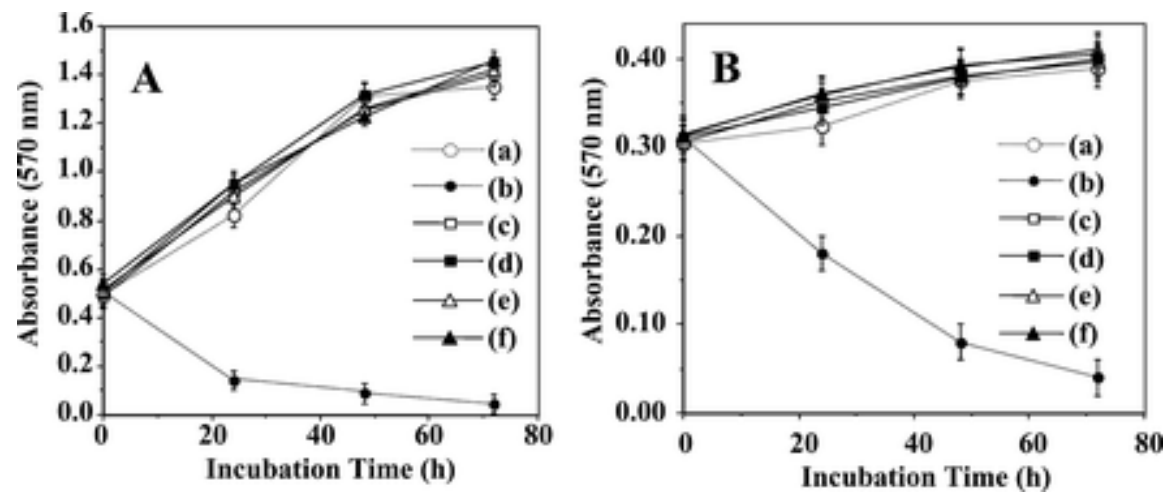

Figure 5 Effect of hybrid molecules on human GECs and GFCs

Hybrid molecules' effect on human GECs (A) and human GFCs (B). Cell viability and proliferation were monitored over time using the MTT assay, as described in the Experimental section by measuring spectrophotometrically the reduced MTT in a dual-beam microtitre plate reader at $570 \mathrm{~nm}$ with a $650 \mathrm{~nm}$ reference. The effect of the presence of (a) the culture medium (control), (b) chlorhexidine, (c) hybrid $A$ at $62.5 \mu \mathrm{M}$, (d) hybrid $\mathrm{A}$ at $250 \mu \mathrm{M}$, (e) hybrid $B$ at $62.5 \mu \mathrm{M}$ (f) or hybrid $B$ at $250 \mu \mathrm{M}$ on cell viability and proliferation is shown.

\section{DISCUSSION}

\section{Tooth enamel-binding peptides as carriers for intra-oral delivery of therapeutics}

The fragment (Asp-Asp-Asp-Glu-Glu) of statherin could be used as a carrier for intra-oral delivery of therapeutic agents. The oral physiological environment could greatly induce the release of the antimicrobial from the tooth surface and in saliva due to the susceptibility of the ester and anhydride bonds. In salivary defence molecules, the antimicrobial sequences are linked by the secondary amide/peptide bond and the release of the antimicrobial requires specific salivary proteolysis. However, microbial invasion results in the inactivation of salivary proteolysis and the secretion of natural antimicrobials. ${ }^{49}$ Therefore, it becomes necessary to deliver antimicrobials intra-orally and to induce a sustained release of the antimicrobial from the tooth surface and in saliva. The ester/anhydride bond in the hybrid might cause a sustained release of the antimicrobial over time without the involvement of any specific enzyme.

Molecules designed to target oral pathogens should be stable in saliva and the antimicrobial component should be released gradually over time to combat microbial colonization. Hybrid $A$ and hybrid $B$ appeared to meet these criteria in vitro, as described in the ${ }^{13} \mathrm{C}-\mathrm{NMR}$ studies (Figure 2A) The high affinity coefficients observed for hybrid $A$ and hybrid $B$ (Table 1 ) indicated that they could be substantially adsorbed on the tooth surface when used topically as a mouth rinse. Hybrid molecules did not appear to be toxic to human cells, including human erythrocytes (Figures 4 and 5).

\section{Intra-oral delivery of antimicrobials}

Caries, gingivitis and periodontal disease still remain the most common infections in humans. The major limitations of the currently available local drug-delivery systems include: (i) adverse events such as dental or gingival pain, soreness, discomfort and sensitivity; (ii) difficulty in inserting or injecting the drug-delivery device around all teeth; (iii) retention of the device at the tooth surface or within the periodontal pockets for a sufficient length of time; (iv) toxic effects and bacterial resistance induced by the conventional antibiotics used in the current devices; and (v) requirement for professional application and high cost. ${ }^{2-4}$ In contrast with the existing formulations that have little to no affinity for the tooth or 
pellicle surface, the bifunctional hybrid molecules could adhere on the tooth and pellicle surfaces uniformly due to the high affinity for the tooth enamel surface, thereby inhibiting microbial accumulation. In addition, these bifunctional molecules would decrease the limitations and discomfort associated with the currently available local drug-delivery devices.

These two bifunctional hybrid molecules could serve as efficient intra-oral antimicrobial delivery systems that may: (i) get adsorbed quickly with high affinity on the tooth and pellicle surfaces; (ii) provide a sustained release of an antimicrobial induced by the oral physiological environment; (iii) block the binding sites on tooth and pellicle surfaces to inhibit bacterial recolonization promoted by the adsorbed salivary proteins; (iv) disrupt bacterial cell membranes leading to cell death due to the presence of the selective natural antimicrobial agent, thereby reducing drug resistance among oral pathogens, and $(v)$ eliminate the discomfort and other disadvantages of the currently available drugdelivery devices. Unlike the local delivery devices that require professional insertion or injection, the hybrids can be easily applied and replenished by rinsing, brushing or irrigation. They could also be used professionally for site-specific applications to sub-gingival areas, if required.

Although new drug-delivery systems such as nanoparticles, microbubbles, mucoadhesives and hydrogels have emerged in recent years, they have not yet been fully developed for intra-oral delivery of antimicrobials. ${ }^{3}$ The results presented in the present paper demonstrate the proof of concept for a novel intra-oral delivery system and validate the previously proposed defence mechanism that exists in the oral cavity. ${ }^{7,13}$ However, further studies are required to validate the in vivo efficacy of intra-oral antimicrobial delivery and safety of these hybrid peptides.

\section{Acknowledgments}

This study was supported by the USPHS (United States Public Health Service) research grant 1R21DE014565-01. We acknowledge Dr T. Karunakaran, formerly of the Department of Oral Biology, and Dr Dinesh K. Sukumaran of the Department of Chemistry, State University of New York at Buffalo (Buffalo, NY, U.S.A.), for their assistance with the microbiological and ${ }^{13} \mathrm{C}-\mathrm{NMR}$ data respectively.

Abbreviations: calcein-AM, calcein-acetoxymethyl ester; DIS, denture-induced stomatitis; $F A B$, fast atom bombardment; FTIR, Fourier-transform infrared; GEC, gingival epithelial cell; GFC, gingival fibroblast cell; HAP, hydroxyapatite; MTT, 3-(4,5-dimethylthiazol-2-yl)-2,5-diphenyl-2H-tetrazolium bromide; NPN, Nphenyl-1-naphthylamine

\section{References}

1. Walker C. B.(1996) The acquisition of antibiotic resistance in the periodontal microflora. Periodontology 10:79-88.

2. Marsh P. D. (2003) Plaque as a biofilm: pharmacological principles of drug delivery and action in the sub- and supragingival environment. Oral Dis. 9:16-22.

3. Raj P. A., Dentino A. R. (2005) Intraoral delivery of antimicrobials. Drug News Perspect. 18:362374.

4. Greenstein G., Polson A. (1998) The role of local drug delivery in the management of periodontal diseases: a comprehensive review. J. Periodontol. 69:507-520. 
5. Brading M. G., Marsh P. D. (2003) The oral environment: the challenge for antimicrobials in oral care products. Int. Dent. J. 53:353-362.

6. Raj P. A., Johnsson M., Levine M. J., Nancollas G. H. (1992) Salivary statherin. Dependence on sequence, charge, hydrogen bonding potency, and helical conformation for adsorption to hydroxyapatite and inhibition of mineralization. J. Biol. Chem. 267:5968-5976.

7. Antonyraj K. J., Karunakaran T., Raj P. A. (1998) Bactericidal activity and poly-L-proline II conformation of the tandem repeat sequence of human salivary mucin glycoprotein (MG2). Arch. Biochem. Biophys. 356:197-208.

8. Raj P. A., Edgerton M., Levine M. J.(1990) Salivary histatin 5: dependence of sequence, chain length, and helical conformation for candidacidal activity. J. Biol. Chem. 265:3898-3905.

9. Raj P. A., Soni S.-D., Levine M. J.(1994) Membrane-induced helical conformation of an active candidacidal fragment of salivary histatins. J. Biol. Chem. 269:9610-9619.

10. Amano A., Sojar H. T., Lee J. Y., Sharma A., Levine M. J., Genco R. J. (1994) Salivary receptors for recombinant fimbrillin of Porphyromonas gingivalis. Infect. Immun. 62:3372-3380.

11. Amano A., Sharma A., Lee J. Y., Sojar H. T., Raj P. A., Genco R. J.(1996) Structural domains of Porphyromonas gingivalis recombinant fimbrillin that mediate binding to salivary proline-rich protein and statherin. Infect. Immun. 64:1631-1637.

12. Amano A., Kataoka K., Raj P. A., Genco R. J., Shizukuishi S.(1996) Binding sites of salivary statherin for Porphyromonas gingivalis recombinant fimbrillin. Infect. Immun. 64:4249-4254.

13. Raj P. A., Antonyraj K. J.(2001) Salivary statherin fragment elicits broad-spectrum antimicrobial activity. J. Dent. Res. 80:629.

14. Raj P. A., Karunakaran T., Sukumaran D. K.(2000) Synthesis, microbicidal activity and solution structure of the dodecapeptide from bovine neutrophils. Biopolymers 53:281-292.

15. Mathews M., Jia H. P., Guthmiller J. M., Losh G., Graham S., Johnson G. K., Tack B. F., McCray P. B. Jr. (1999) Production of $\beta$-defensin antimicrobial peptides by the oral mucosa and salivary glands. Infect. Immun. 67:2740-2745.

16. Sahasrabudhe K. S., Kimball J. R., Morton T. H., Weinberg A., Dale B. A.(2000) Expression of the antimicrobial peptide $\beta$-defensin 1 in duct cells of minor salivary glands and detection in saliva. J. Dent. Res. 79:1669-1674.

17. Murakami Y., Nagata H., Amano A., Takagaki M., Shizukuishi S., Tsunemitsu A., Aimoto S.(1991) Inhibitory effects of human salivary histatins and lysozyme on coaggregation between Porphyromonas gingivalis and Streptococcus mitis. Infect. Immun. 59:3284-3286.

18. Raj P. A., Antonyraj K. J., Karunakaran T. (2000) Large-scale synthesis and functional elements for antimicrobial activity of defensins. Biochem. J. 347:633-641.

19. Murakami M., Ohtake T., Dorschner R. A., Gallo R. L. (2002) Cathelicidn antimicrobial peptides are expressed in salivary glands and saliva. J. Dent. Res. 81:845-850.

20. Johnsson M., Richardson C. F., Bergey E. J., Levine M. J., Nancollas G. H.(1991) The effects of human salivary cystatins and statherin on hydroxyapatite crystallization. Arch. Oral Biol. 36:631636.

21. Stewart J. M., Young J. D.(1984) Solid Phase Peptide Synthesis (Pierce Chemical Company, Rockford), pp 71-103.

22. Edgerton M., Raj P. A., Levine M. J. (1995) Surface-modified poly methyl methacrylate enhances adsorption and retains anticandidal activities of salivary histatin 5. J. Biomed. Mat. Res. 29:1277-1286. 
23. Wehrli F. W., Wirthlin T.(1976) Interpretation of Carbon-13 NMR Spectra (Heydon and Son, New York), pp 264-275.

24. Wüthrich K.(1986) NMR of Proteins and Nucleic Acids (John Wiley, New York).

25. Zombon J. J., Reynolds H. S., Genco R. J.(1990) Studies of the subgingival microflora in patients with immunodeficiency syndrome. J. Periodontal. 61:699-704.

26. Reichart P. A.(2000) Oral mucosal lesions in a representative cross-sectional study of aging Germans. Commun. Dent. Oral Epidemiol. 28:390-398.

27. Moskona D., Kaplan I.(1992) Oral lesions in elderly denture wearers. Clin. Prev. Dent. 14:11-14.

28. Ouhara K., Komatsuzawa H., Yamada S., Shiba H., Fujiwara T., Ohara M., Sayama K., Hashimoto K., Kurihara H., Sugai M.(2005) Susceptibilities of periodontopathogenic and cariogenic bacteria to antibacterial peptides, $\beta$-defensins and LL37, produced by human epithelial cells. J.

Antimicrob. Chemother. 55:888-896.

29. Shellis R. P.(1978) A synthetic saliva for cultural studies of dental plaque. Arch. Oral. Biol. 23:485-489.

30. Edgerton M., Koshlukova S. E., Lo T. E., Chrzan B. G., Straubinger R. M., Raj P. A.(1998) Candidacidal activity of histatins: identification of an histatin 5 binding protein on Candida albicans. J. Biol. Chem. 273:20438-20447.

31. Raj P. A., Marcus E., Edgerton M. (1996) Delineation of an active fragment and poly(L-proline) II conformation for candidacidal activity of bactenecin 5. Biochemistry 35:4314-4325.

32. Loh M., Grant C., Hancock R. E. W.(1984) Use of fluorescent probe 1-N-phenylnaphthylamine to study the interaction of aminoglycoside antibiotics with the outer membrane of Pseudomonas aeruginosa. Antimicrob. Agents Chemother. 19:546-551.

33. Wu M., Hancock R. E. W.(1999) Interaction of the cytoplasmic cationic peptide bactenecin with the outer and cytoplasmic membrane. J. Biol. Chem. 274:29-35.

34. Lance M. R., Washington C., Davis S. S.(1995) Structure and toxicity of amphotericin B/triglyceride emulsion formulations. J. Antimicrob. Chemother. 36:119-128.

35. Oda D., Watson E.(1990) Human oral epithelial cell culture. Improved condition for reproducible culture in serum-free medium. In Vitro Cell. Dev. Biol. 26:589-595.

36. Chang Y. C., Tai K. W., Cheng M. H., Chou L. S. S., Chou M. Y.(1998) Cytotoxic and non-genotoxic effects of arecoline on human buccal fibroblasts in vitro. J. Oral Pathol. Med. 27:68-71.

37. Lamont R. J. D., Oda D., Persson R. E., Persson G. R. (1992) Interaction of Porphyromonas gingivalis with gingival epithelial cells maintained in culture. Oral Microbiol. Immunol. 7:364367.

38. Huang F. M., Tai K. W., Hu C. C., Chang Y. C.(2001) Cytotoxicity effects of denture base materials on a permanent human oral epithelial cell line and on primary human oral fibroblasts in vitro. Int. J. Prosthodont. 14:439-443.

39. Eick J. D., Kostoryz E. L., Rozzi S. M., Jacob D. W., Oxman J. D., Chappelow C. C., Glaros A. G., Yourtee D. M.(2002) In vitro biocompatibility of oxirane/polyol dental composites with promising physical properties. Dent. Mater. 18:413-421.

40. Mosmann T.(1983) Rapid colorimetric assay for cellular growth and survival: application to proliferation and cytotoxicity assays. J. Immunol. Methods 65:55-63.

41. Chang Y. C., Tai K. W., Chou L. S. S., Chou M. Y. (1999) Effects of camphorated parachlorophenol on human periodontal ligament cells in vitro. J. Endodontics 25:179-281. 
42. Raj P. A., Dentino A. R.(2002) A novel bifunctional molecule targets oral pathogens. J. Dent. Res. 81:481.

43. Raj P. A., Rajkumar L., Dentino A. R.(2004) New and novel technology for intra-oral delivery of antimicrobials. J. Dent. Res. 83:1468.

44. Krimm S., Bandekar J.(1986) Vibrational spectroscopy and conformation of peptides, polypeptides, and proteins. Adv. Protein Chem. 38:181-364.

45. Kahn P. C.(1979) The interpretation of near-ultraviolet circular dichroism. Methods Enzymol. 61:339-376.

46. Kresak M., Moreno E. C., Zahradnik R. T., Hay D. I.(1977) Adsorption of amino acids onto hydroxyapatite. J. Colloid Interface Sci. 59:283-292.

47. Pucher J. J., Daniel J. C.(1992) The effect of chlorhexidine digluconate on human fibroblasts in vitro. J. Periodontol. 63:526-532.

48. Babich H., Wurzberger B. J., Rubin Y. L., Sinensky M. C., Blau L.(1995) An in vitro study on the cytotoxicity of chlorhexidine gluconate to human gingival cells. Cell Biol. Toxicol. 11:79-88.

49. Weinberg A., Krisanaprokornkit S., Dale B. A.(1998) Epithelial antimicrobial peptides: review and significance for oral applications. Crit. Rev. Oral Biol. Med. 9:399-414 